\title{
TLR9 signaling activation at different stages in colorectal cancer and NF-kappaB expression
}

This article was published in the following Dove Press journal:

OncoTargets and Therapy

\section{Caixia Gao \\ Tiankui Qiao \\ Bin Zhang \\ Sujuan Yuan \\ Xibing Zhuang \\ Youjun Luo}

Department of Oncology, Jinshan Hospital of Fudan University, Shanghai, People's Republic of China
Correspondence: Tiankui Qiao Department of Oncology, Jinshan Hospital of Fudan University, No 1508 Longhang Road, Jinshan District, Shanghai 20I508, People's Republic of China

Tel +86 I8930778786

Email qiaotk@l63.com
Background: The relationship of inflammation and tumor is becoming more and more important in the study on the pathogenesis of colorectal cancer. The role of TLR9-mediated immune inflammation reaction in the process is not currently clear. The purpose of the study was to discuss the correlation of TLR9 signal activation with tumor progression by detecting the expression of TLR9 and its downstream molecule NF-kappaB in colorectal cancer tissues at different stages.

Methods: TLR9 expression in colorectal cancer tissues was detected by immunohistochemical streptavidin-perosidase method and Western blot.

Results: The result showed that the high expression of TLR9 was correlated with tumor poorly differentiation, invasion and liver metastasis, the abnomal increasing levels of CEA in blood. With the signal activation, the levels of TLR9 protein raised more in advanced colorectal cancer than in early colorectal cancer. Afterward, we found that the activation of specific expression of TLR9 signal was related to histologic origin. TLR9-C expression displayed in both advanced cancer and para-carcinoma tissues, and TLR9-R protein was predominat in partial sigmoid and rectal cancer tissues. With the differential expression of TLR9, the levels of its downstream molecule NF-kappaB protein increased in colon cancer tissues and decreased in rectal cancer tissues.

Conclusion: The results confirmed that TLR9 signaling activation participated in the clinical process of colorectal cancer and influenced NF-kappaB expression.

Keywords: bowel tumor, TLR9 signaling activation, the differential expression, NF-kappaB

\section{Introduction}

With lifestyle changes, the number of patients with colorectal cancer has been increased year by year. According to a recent data, ${ }^{1}$ the incidence of male and female colorectal cancers is up to the second and third positions in all malignant tumors, respectively, which is even more in big cities in People's Republic of China. The current clinical treatment of colorectal cancer remains unsatisfactory due to early postoperative local recurrence and metastasis.

Hyperplasia-neoplasia-cancerous of intestinal epithelial has been reported most frequently in inflammation associated tumorigenesis mechanism research. ${ }^{2}$ Several studies confirmed that TLRs as immune molecules mediated inflammatory response and played an important role in this process. ${ }^{3}$ TLR9 belongs to the intracellular receptor, whose ligand is the unmethylated CpG DNA in bacteria and viruses. TLR9 is one of the TLRs and a ligand based on nucleic acid ingredients. Activation of TLR9 signaling pathway can induce Th1 immune response and stimulate proliferation of B cells, promoting IgM secretion at the same time so as to play a part in natural immune response against invasion of microbes outside. ${ }^{4-6}$ Moreover, at present, TLR9 expression in various tumor cells have been demonstrated sequentially, ${ }^{7-10}$ and activation of TLR9 signal pathway takes part in the generation, development and metastasis of tumor. ${ }^{11}$ 
It is proved that TLR9 signaling activation is a classical toll-like signal conduction pathway. ${ }^{12}$ With polymerization process after TLR9 and its ligand binding, nuclear transcription factors AP-1 and NF-kappaB are activated by MYD88dependent and TRIF-dependent signaling pathways. The research from Xu et al ${ }^{13,15}$ and Ren et $\mathrm{al}^{14}$ demonstrated that upregulation of TLR9 expression facilitated the proliferation of tumor cells sharply under the ligand in lung cancer. ${ }^{13-15}$ With TLR9 signal activation promoting inflammatory factor such as IL-1, IL-8 upregulation and increasing immune inhibitory factor IL-10 secretion and MMP-2, chemokine receptor two and cell adhesion molecule one expression, the ability in invasion and metastasis of lung cancer cells were enhancement. CpG ODN increasing MMP expression via TLR9 to strengthen the invasion and metastasis of prostate cancer cell also was confirmed. ${ }^{16}$ It was reported that TLR9 expression is detected in multiple tissues. ${ }^{17}$ The relationship of TLR9 expression in colorectal cancer and the clinical tumor development was not reported. In this paper, by detecting TLR9 and NF-kappaB expression in cancer and adjacent to carcinoma tissues at various stages, we examined TLR9 signaling activation in advanced colorectal carcinoma and surveyed the effect on the downstream molecule NF-kappaB.

\section{Materials and methods Collection of cases and preparation of experimental materials \\ Collection of cases}

The tumor specimens were obtained from 86 patients admitted for diagnosis and treatment in Jinshan Hospital of Fudan University from January 1, 2012, to October 31, 2013. The diagnosis was made according to WHO criteria. The conditions selected were as follows: proven primary colorectal cancer pathologically with preoperative colonoscopy, underwent primary tumor resection operation and mesenteric lymph nodes cleaning apart from laparoscopic surgery, without preoperative radiochemotherapy, requirement of informed consent for surgical treatment and experimental study on postoperative tissues and the complete postoperative pathological files. In all, 86 patients were recruited, of whom 44 were males and 42 females. The oldest patient was 89 years old, and the youngest patient was 42 years old. The median age was 69 years. The levels of CEA in the blood of patients were examined before the operation. The study was approved by and performed in accordance with the protocols of the ethics committee of Jinshan Hospital of Fudan University (Shanghai, China), together with the confirmation that all patients whose tissues were used provided written informed consent.

\section{Experimental materials}

A total of 11 samples of colorectal cancer and the adjacent tissues were taken by surgeons from resection fresh issues of the patients and labeled as $\mathrm{C}-1, \mathrm{C}-2, \ldots, \mathrm{C}-10$ and $\mathrm{C}-11$. The degree of tumor resection was defined as follows: carcinoma tissues with no obvious necrosis and fibrous adipose tissues; the tissues adjacent to carcinoma were defined more than $5 \mathrm{~cm}$ distance carcinoma tissues, as far as possible without fibro-fatty tissues. According to the principles of American Joint Committee on Cancer (AJCC) and International Union Against Cancer (UJCC) in 1997, C-1 and C-7 were attributed to clinical stage I, C-4, C-5 and C-6 to clinical stage II, C-11 to clinical stage IV and the others to clinical stage III. Then, the fresh tissues were collected in microtubes and stored in liquid nitrogen. Finally, they were stored at $-80^{\circ} \mathrm{C}$ for future use. The samples were obtained with the consent of patients and their family members.

\section{Experimental methods}

\section{Immunohistochemical streptavidin-perosidase method}

A total of 86 wax blocks of colorectal cancer tissues were cut into sections of $4 \mu \mathrm{m}$, fixed and labeled. The sections deparaffinized and hydrated were submerged into EDTA $(\mathrm{pH}=6.0)$, and irradiation with microwave was performed for antigen retrieval, treated with 3\% hydrogen peroxide, followed by incubation with $1 \%$ FBS. Diluted primary antibody (ab12121, mouse TLR9 monoclonal antibody 1:100; Abcam, Cambridge, UK) was added and incubated overnight at $4{ }^{\circ} \mathrm{C}$. PBS was substituted for the primary antibody as a negative control. HRP-Polymer Antimouse Immunohistochemistry (IHC) Kit (KIT-5930 Maixin Biology, Fuzhou, China) was applied and incubated for 30 minutes at room temperature, followed by 5 minutes incubation at room temperature with diaminobenzidine for color development. The sections were finally counterstained with hematoxylin and mounted with Permount. The determination of result was based on scores combining the proportion of stained tumor cells and the intensity. The proportion of stained tumor cells was graded as follows: 0 (no stained tumor cells), $1(<10 \%$ stained tumor cells), $2(10 \%-50 \%$ stained tumor cells) and $3(>50 \%$ stained tumor cells). The intensity of stain was recorded on a scale of 0 (no staining), 1 (weak staining, light yellow), 2 (moderate staining, yellowish brown) and 3 (strong staining, brown). The staining index was calculated as follows: staining index=staining intensity+score of stained tumor cells. The staining index score $\geq 4$ was defined as a high expression of TLR9 and the staining index score $<4$ as a low expression of TLR9. 


\section{Tissue protein extraction and Western blot}

A total of $100 \mathrm{mg}$ sections of cancerous and paracancerous tissues from 11 samples were prepared and cut into pieces. With cracking and tissue homogenate on ice, they were centrifuged for 15 minutes at $15,500 \mathrm{rpm}$ at $4^{\circ} \mathrm{C}$. The supernatant was the protein of interest. Protein concentration was determined by the bicinchoninic acid method. Protein extracts were separated by $10 \%$ SDS-PAGE, transferred to polyvinylidene difluoride (PVDF) membranes (EMD Millipore, Billerica, MA, USA), blocked with 10\% nonfat dry milk in tris-buffered saline (TBS) containing $0.1 \%$ Tween-20 (TBS-T) for 2.5 hours at room temperature and then incubated with the following primary antibodies at $4{ }^{\circ} \mathrm{C}$ overnight (ab125139, rabbit TLR9 polyclonal antibody 1:1,000 [Abcam]; ab76302, rabbit NF-kappaBp65 monoclonal antibody 1:10,000 [Abcam]; mouse GAPDH antibody 1:5,000 [Abcam]). Membranes were washed with TBS-T three times and probed with secondary antibodies for 2 hours at room temperature. Protein bands were visualized using chemiluminescence HRP substrate (EMD Millipore).

\section{Statistical analyses}

SPSS 17.0 statistical software (SPSS, Inc., Chicago, IL, USA) was used for all statistical analyses. Measurement data were presented as $x \pm s$, and differences among groups were compared with analysis of variance. The correlation between TLR9 high expression and the clinicopathological features was tested using the chi-squared test. The statistical graphics were made by GraphPad Prism 5.0 software (GraphPad Software, Inc., La Jolla, CA, USA), and $P<0.05$ was considered as statistically significant.

\section{Results TLR9 expression in cancer tissues of 86 cases}

A total of 53 of the patients were diagnosed with colon tumor, among whom there were 19 suffering from tumor of right colon (including ileocecum) and 34 from tumor of other parts except for ascending colon. In all, 33 of the patients were diagnosed with rectal carcinoma. There were 33 patients with lymph node metastasis, 14 patients with distant metastasis such as liver metastasis and 34 patients with a history of intestinal schistosomiasis or liver schistosomiasis. TLR9 proteins were distributed evenly in the cytoplasm of cancer cells with tan or sepia color, as shown in Figure 1. The total rate of TLR9 high expression in 86 samples was $41.9 \%$, which was not statistically significant in gender $(40.9 \%$ and $42.9 \%, P=0.85)$ and age (33.3\% and $45.5 \%, P=0.25)$. The ratios of TLR9 high expression in carcinoma tissues of colon and rectum were $49.1 \%$ and $30.3 \%$, respectively, $P=0.09$, without statistical discrepancy.
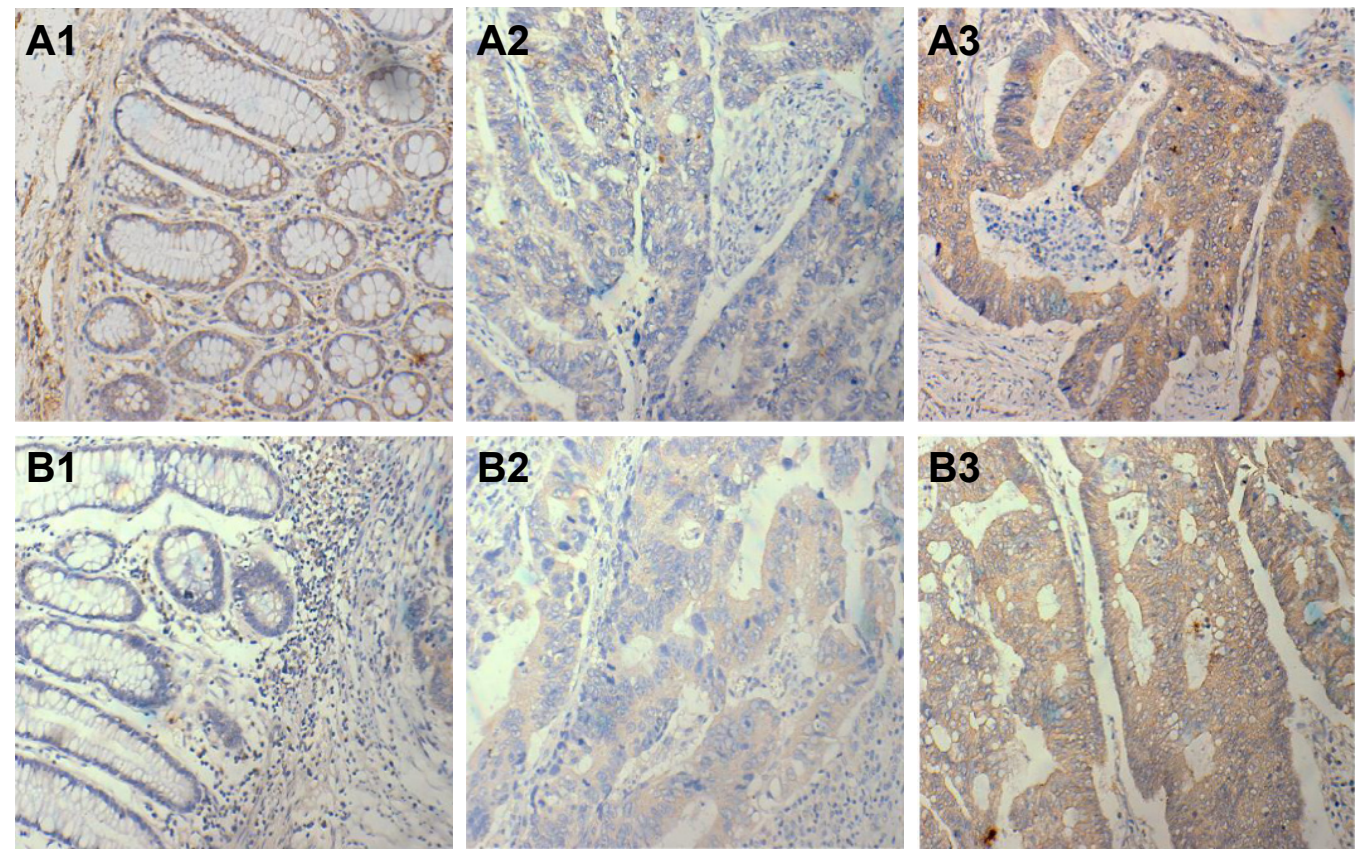

Figure I TLR9 expression in colorectal cancer tissues.

Notes: TLR9 expression in colorectal cancer tissues (immunohistochemical streptavidin-perosidase method, $\times 400$ ) and TLR9 expression in colorectal cancer tissues were examined (diaminobenzidine; magnification, $\times 400$ ). Compared with normal intestinal epithelial cells, tumor cells became larger in volume and were arranged irregularly with disorder. TLR9 protein distributing equality in cytoplasm of tumor cells increased distinctly with unusual karyomegaly, multi leaf nuclei and thickening of nuclear envelope etc. (AI) Colon para-carcinoma tissues, (A2-3) colon cancer tissues, (BI) rectal para-carcinoma tissues and (B2-3) rectal cancer tissues. 
Table I Correlation of TLR9 expression in cancer tissues and histological features

\begin{tabular}{|c|c|c|c|c|c|}
\hline & \multirow[t]{2}{*}{ Number } & \multicolumn{2}{|c|}{ TLR9 expression } & \multirow[t]{2}{*}{$\chi^{2}$} & \multirow[t]{2}{*}{$P$-value } \\
\hline & & Low (\%) & High (\%) & & \\
\hline Histological differentiations & & & & 7.068 & 0.0292 \\
\hline Well differentiated & 14 & $12(85.7)$ & $2(14.3)$ & & \\
\hline Moderately differentiated & 62 & $30(48.4)$ & $32(51.6)$ & & \\
\hline Poorly differentiated & 4 & $3(75.0)$ & I (25.0) & & \\
\hline Depth of infiltration $(T)$ & & & & 20.210 & 0.0001 \\
\hline $\mathrm{TI}-\mathrm{T} 2$ & 30 & $27(90.0)$ & $3(10.0)$ & & \\
\hline T3 & 48 & $21(43.7)$ & $27(56.3)$ & & \\
\hline $\mathrm{T} 4$ & 8 & $2(25.0)$ & $6(75.0)$ & & \\
\hline Lymph node metastasis $(\mathrm{N})$ & & & & 3.540 & 0.0599 \\
\hline Negative & 53 & $35(66.0)$ & I $8(44.0)$ & & \\
\hline Positive & 33 & I5 (45.5) & I8 (54.5) & & \\
\hline Liver metastasis (M) & & & & 9.260 & 0.0023 \\
\hline Negative & 72 & $47(65.3)$ & $25(34.7)$ & & \\
\hline Positive & 14 & $3(21.4)$ & II (78.6) & & \\
\hline Infection by schistosoma & & & & 0.304 & 0.5816 \\
\hline Negative & 52 & $29(55.8)$ & $23(44.2)$ & & \\
\hline Positive & 34 & $21(61.8)$ & $13(38.2)$ & & \\
\hline
\end{tabular}

Notes: Based on the principles of American Joint Committee on Cancer (AJCC) and International Union Against Cancer (UJCC) in I997, the criteria of newly revised TNM staging were adopted to clinical stage of colorectal cancer. By chi-square statistics, we observed that a high expression of TLR9 was related to moderate-poor differentiation, tumor invasion (T3-T4) and metastasis; the P-values were $0.0292,0.0001$ and 0.0023 , respectively. The result implied that TLR9 signaling activation was connected with tumor progression in advanced colorectal cancer.

\section{Correlation of TLR9 expression in colorectal cancer tissues and histological grades}

Based on histopathological results, the correlation of TLR9 high expression in colorectal cancer tissues and tumor cell differentiation, infiltration depth $(\mathrm{T})$, lymph node and liver metastasis and schistosomiasis infection was analyzed. As shown in Table 1, a high expression of TLR9 was correlated with moderate-poor differentiation and invasive depth (T3-T4) of tumor; the $P$-values were 0.0292 and 0.0001 , respectively. The ratios of TLR9 high expression relative to positive lymph node and liver metastasis were $54.5 \%$ and $78.6 \%$ ( $P=0.0599$ and 0.0023 , respectively), respectively, showing the correlation between TLR9 high expression in colorectal cancer tissues and tumor invasion and metastasis. The relationship of TLR9 high expression and schistosomiasis infection was statistically not significant.

\section{Relationship between TLR9 expression and the abnormal increase in CEA pre operation}

According to the reference ranges of CEA $(0-5 \mathrm{ng} / \mathrm{mL})$ in blood in our hospital, the correlation between TLR9 expression and the proportion of patients on CEA $(>5 \mathrm{ng} / \mathrm{mL})$ that increased during pre operation is shown in Figure 2. Among patients with TLR9 expression scoring 4-6 points, the proportion of patients with $>5 \mathrm{ng} / \mathrm{mL}$ of CEA in blood was $47.4 \%, 61.5 \%$ and $100 \%$, respectively, while in patients with TLR9 expression scoring 1-3 points, this ratio seemed to be decreasing $(14.3 \%, 10.0 \%$ and $18.8 \%$, respectively). Spearman correlation coefficient was 0.9643 , and the $P$-value was 0.0028 statistically. It turned out that the abnormal increase in CEA in blood pre operation was related to TLR9 high expression in cancer tissues. The $R^{2}$ value of the curve using the correlation fitting method was 0.9786 .

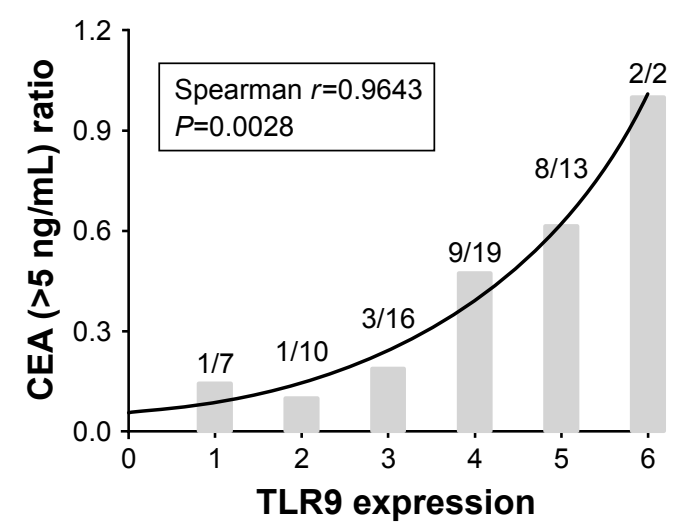

Figure 2 The relationship between TLR9 expression in cancer tissues and the ratio of patients on increasing CEA $(>5 \mathrm{ng} / \mathrm{mL})$ in blood.

Notes: The curve-fitting statistical analysis was used in dealing with the relationship of TLR9 expression in cancer tissues and the ratio of patients on increasing CEA $(>5 \mathrm{ng} / \mathrm{mL})$ pre operation. The number in the diagram is the ratio of CEA $(>5 \mathrm{ng} / \mathrm{mL})$ corresponding to TLR9 expression score, becoming added with high expression of TLR9. Spearman correlation coefficient was 0.9643 , and the $P$-value was 0.0028 . The $R^{2}$ value of the curve using the correlation fitting method was 0.9786 . This result illustrated that TLR9 signal activation emerged more easily in colorectal cancer with an abnormal increase in CEA. 


\section{TLR9 signaling activation in advanced colorectal cancer and para-carcinoma tissues}

TLR9 expression in cancer and adjacent tissues from resection of patients with colorectal cancer were tested by Western blot in order to examine TLR9 signaling activation in colorectal cancer. As shown in Figure 3A, we noticed that the levels of TLR9 protein in cancer and para-carcinoma tissues increased in advanced colorectal cancer of C-3, C-8,
C-9, C-10, C-2 and C-11 (clinical stages III and IV) than in early cancer of C-5, C-7 and C-1 (stages II and I). This result was meaningful to understand that TLR9 signal was activated more in advanced colorectal cancer than that in early colorectal cancer. Moreover, TLR9 protein manifested variation performance in different locations of intestine with the signal activation. With TLR9 protein bands of molecular weight $110-120 \mathrm{kDa}$ in colon cancer tissues predominantly and $100-110 \mathrm{kDa}$ in rectal carcinoma tissues mainly after

A
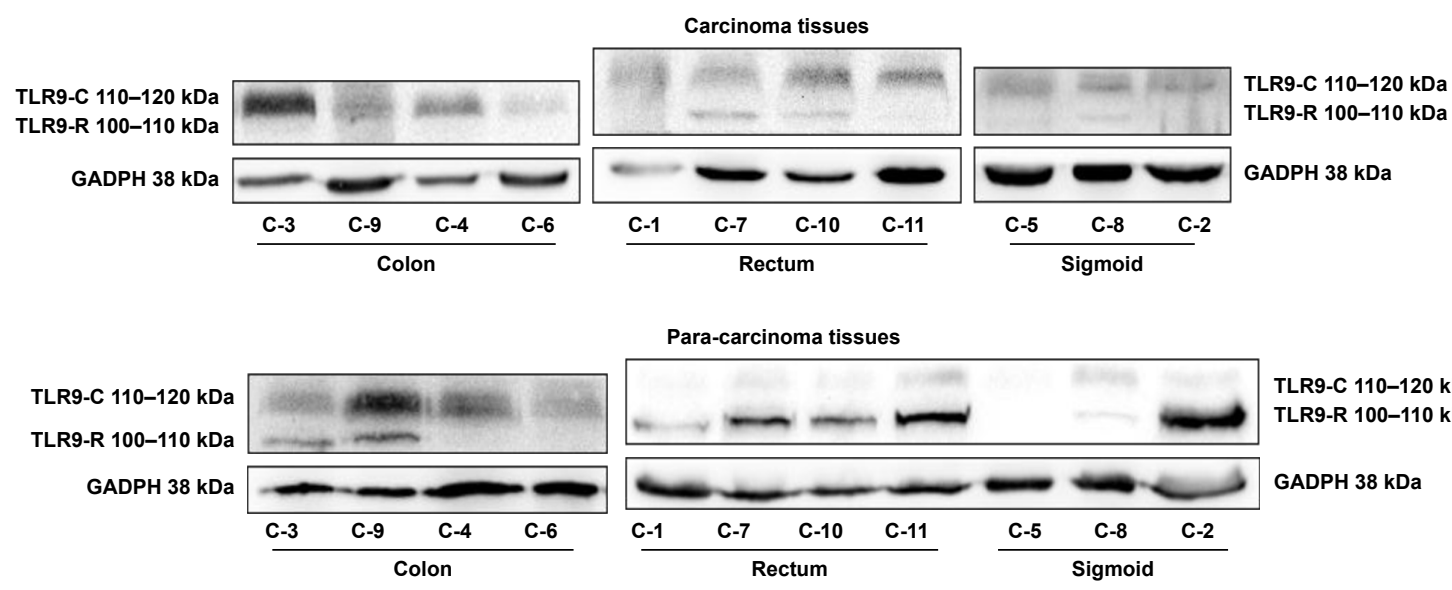

TLR9-C 110-120 kDa

TLR9-R 100-110 kDa

GADPH 38 kDa

B

Para-carcinoma tissues
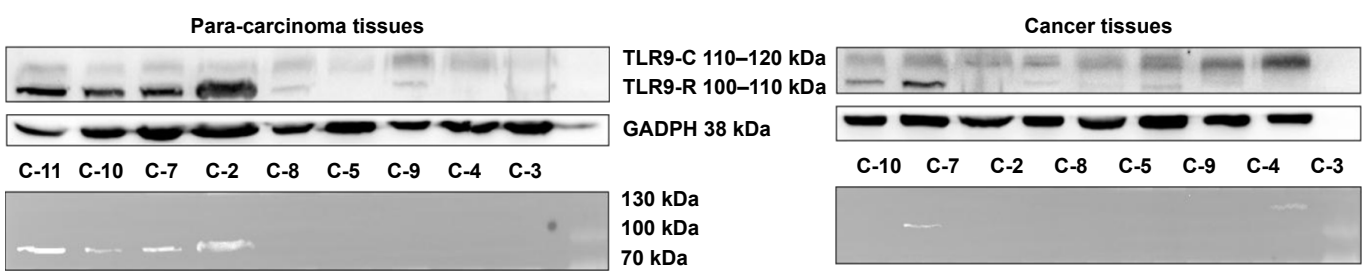

TLR9-C 110-120 kDa TLR9-R 100-110 kDa GADPH 38 kDa

C Para-carcinoma tissues
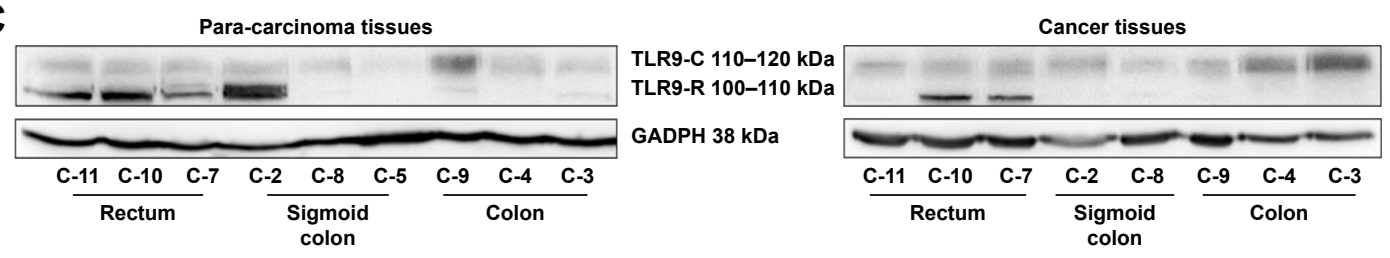

$130 \mathrm{kDa}$ $100 \mathrm{kDa}$ $70 \mathrm{kDa}$
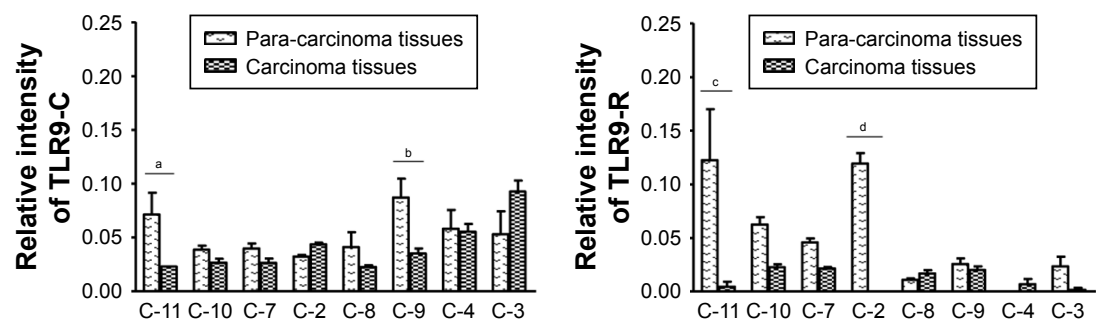

Figure 3 The differential expression of TLR9 signaling activation in colorectal cancer and para-carcinoma tissues.

Notes: (A) TLR9 expression in colorectal cancer and para-carcinoma tissues by Western blot. (B) The differential expression of TLR9 in colorectal cancer and paracarcinoma tissues with different molecular weights. (C) Expression of TLR9-C and TLR9-R in advanced colorectal cancer and para-carcinoma tissues. Detected by Western blot, the levels of TLR9 protein in cancer and para-carcinoma tissues increased more in advanced colorectal cancer than in early colorectal cancer (A). The differential expression of TLR9 associated with organic locations is displayed in (B). As shown in (C), TLR9-C protein exhibited in both colorectal cancer and para-carcinoma tissues, and the levels of TLR9-R protein raised much more in adjacent cancer tissues of partial sigmoid and rectum than those in colon tissues. Compared with the levels of TLR9-R protein in cancer tissues, the levels of TLR9-R protein in para-carcinoma tissues of C-II and C-2 (clinical stage IV and III respectively) were statistically significant; the $t$-values were 6.905 and 7.002, respectively, both $P<0.00 \mathrm{I}$. a, $t=3.545, P<0.05$; b, $t=3.814, P<0.05 ; \mathrm{c}, t=6.905, P<0.00 \mathrm{I}$ and $d, t=7.002, P<0.00 \mathrm{I}$. 
the signal activation, two TLR9 strips were respectively named as TLR9-C (molecular weight 110-120 kDa) and TLR9-R (molecular weight $100-110 \mathrm{kDa}$ ), as shown in Figure 3. Using statistical analysis on the levels of TLR9-C and TLR9-R proteins in advanced colorectal cancer and paracarcinoma tissues, we found that TLR9-C expression exposed in cancer tissues and the tissues adjacent to cancer. The levels of TLR9-C protein in cancer and para-carcinoma tissues of C-9 and C-11 (clinical stages III and IV, respectively) were of statistical significance $(P<0.05)$. However, the levels of TLR9-R protein in adjacent tissues of the part of sigmoid and rectum cancer were much more than those in carcinoma tissues, of which C-11 and C-2 (clinical stages IV and III, respectively) were statistically significant (both $P<0.001$; Figure 3).

\section{NF-kappaB expression in colorectal cancer and adjacent tissues with TLR9 signaling activation}

With TLR9 signaling activation, NF-kappaB expression in colon cancer and the adjacent tissues at different stages is shown in Figure 4A. The levels of NF-kappaB protein increased in colon cancer and para-carcinoma tissues with upregulation of TLR9-C expression. TLR9-R expression was low or zero in colon cancer and para-carcinoma tissues. According to bi-variant relation analysis, the levels of NFkappaB protein were associated with TLR9-R expression, in which $t$-values of C-4, C-3 (clinical stages II and III) in cancer tissues and C-9 (clinical stage III) in adjacent tissues were 4.002, 5.091 and 4.002, respectively, above $P<0.01$. Yet, similar increasing levels of NF-kappaB protein were
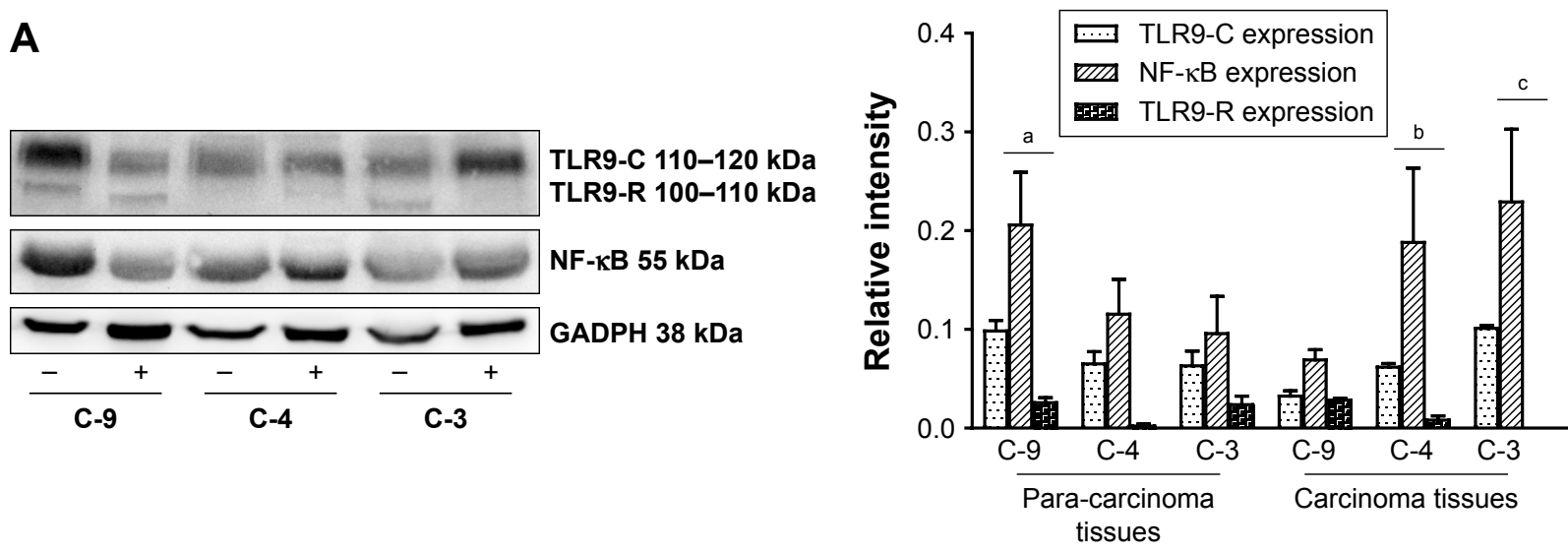

B

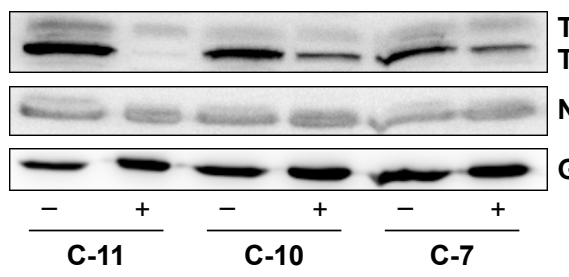

TLR9-C 110-120 kDa TLR9-R 100-110 kDa NF-kB 55 kDa GADPH 38 kDa

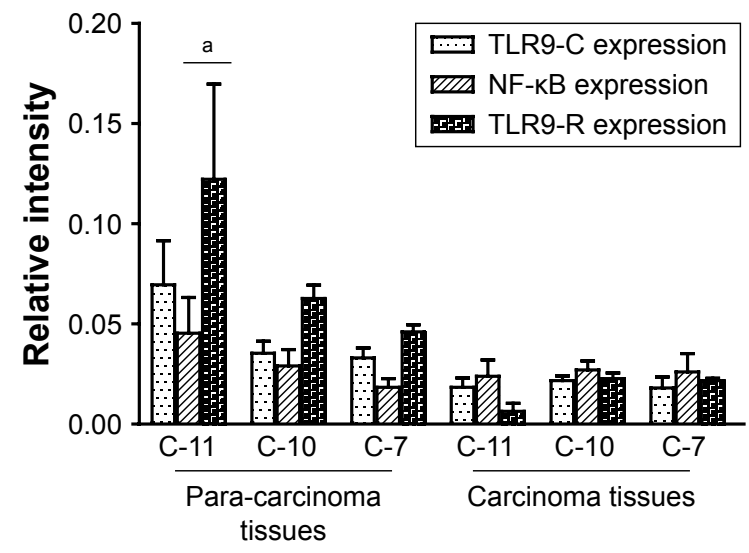

Figure 4 Expression of TLR9-C, TLR9-R and NF-kappaB in colorectal cancer and para-carcinoma tissues.

Notes: (A) Expression of TLR9-C, TLR9-R and NF-kappaB in colon cancer and para-carcinoma tissues. "+" and "-" refer to cancer tissues and para-carcinoma tissues, respectively. a, $t=4.002(P<0.00 \mathrm{I})$; b, $t=4.002(P<0.0 \mathrm{I})$ and $\mathrm{c}, t=5.09 \mathrm{I}(P<0.00 \mathrm{I})$. (B) Expression of TLR9-C, TLR9-R and NF-kappaB in rectal cancer and para-carcinoma tissues. The levels of the downstream molecule NF-kappaB protein was tested in advanced colorectal cancer tissues. "+" and "-" refer to cancer tissues and para-carcinoma tissues, respectively. a, $t=6.188(P<0.001)$. As shown in $(\mathbf{A})$, the levels of NF-kappaB protein in colon cancer tissues increased with upregulation of TLR9-C expression and low or no expression of TLR9-R, of which C-9 (clinical stage II) in para-carcinoma and C-4 and C-3 (clinical stages II and III) in cancer tissues were related to TLR9-R expression; the $t$-values were 4.002, 4.002 and 5.09I, respectively $(P<0.01$ and $P<0.001)$. NF-kappaB expression in rectal cancer tissues is shown in (B). Compared with the levels of NF-kappaB protein in colon cancer tissues, the levels of NF-kappaB protein were low in rectum para-carcinoma tissues with a high expression of TLR9-R. The levels of NF-kappaB protein of C-I I (clinical stage IV) in tissues adjacent to cancer had a correlation with a high expression of TLR9-R; the $t$-value was 6. I88 ( $<<0.00 \mathrm{I})$. 
not present in rectum cancer and para-carcinoma tissues. As shown in Figure 4B, NF-kappaB kept low expression at various stages in rectal cancer and para-carcinoma tissues with the levels of TLR9-R protein raising in the adjacent tissues of rectum cancer. Based on bi-variant relation analysis, the levels of NF-kappaB protein in the adjacent tissues of C-11 (clinical stage IV) was related to TLR9-R; the $t$-value was $6.188(P<0.001)$.

\section{Discussion}

TLR9 was first named in 2000, being isolated cDNA in mice and humans, by the Japanese scholar Hemmi et al. ${ }^{18}$ It has been proved that TLR9 is the receptor CpG DNA in bacteria exerted immune stimulation effect. TLR9 belongs to pattern recognition receptor. It is agreed that TLR9 signal activationmediated immune response has affected tumor development and played a role in oncotherapy. Because of hypoxia and necrosis in tissue center caused by a rapid growth of tumor cells, a large number of cell debris and protein release and become endogenous DAMPs. PAMPs or DAMPs activate TLR9 and its downstream signaling pathways, promote a series of inflammatory cytokines' synthesis and release and contribute to tumor immune microenvironment remodeling to influence tumor development and prognosis of patients. The correlation of TLR9 expression in cancerous tissues and clinical stages, pathological grades and lymph node metastasis in breast cancer, liver cancer, glioma and prostate cancer was reported. ${ }^{19-22}$ Väisänen et $\mathrm{al}^{22}$ confirmed that the patients with prostate cancer suffered from higher clinical recurrence and worse consequence from TLR9 high expression. Equally, the patients with TLR9 high expression in esophageal cancer and glioma tissues had a poor prognosis. ${ }^{23,24}$ However, researchers reported that missing TLR9 expression became a poor prognosis factor in renal cell carcinoma and triple-negative breast cancer. ${ }^{25-27}$ Eiró et al ${ }^{28}$ thought that TLR9 may protect the intestinal mucosa cells from neoplasia to cancer because of TLR9 expression changing from high to low in the process of high-grade neoplasia and adenomatous polyp to colorectal cancer. This makes the impact on tumor progression of TLR9 signal activation become misty. In this study, we detected the expression of TLR9 and its downstream molecule NF-kappaB in colorectal cancer tissues at different stages and explored the relationship of TLR9 signal activation and the clinical pathological development of colorectal cancer.

First of all, TLR9 expression in colorectal cancer tissues of 86 cases were detected by IHC. The results showed that normal intestinal epithelial cells were regular and sharp with
TLR9 low expression. Tumor cell became large in volume and were arranged irregularly with disorder. TLR9 protein distributing equally in cytoplasm of tumor cell increased distinctly with unusual karyomegaly and multi leaf nuclei and thickening of nuclear envelope etc. Then, we observed the relevance of TLR9 high expression and poorly histological grades, tumor invasion and liver metastasis and the preoperative abnormal increase in CEA in blood. It suggested that TLR9 signal activation was more susceptible to occur in advanced colorectal cancer than in early colorectal cancer.

TLR9 belongs to the type I transmembrane protein. TLR9 sequences have typical TLR structure, which is the conservative area in the TLRs family. It has leucine-rich repeats and TIR domain containing 25 amino acid residues in the $\mathrm{N}$ terminal, starting from the 819 (human) or 820 (rat) to the following 18 residues in the transmembrane area. ${ }^{29}$ The functional receptors resulting from the hydrolysis of TLR9 fulllength protein have been demonstrated in multiple studies. Chockalingam et $\mathrm{al}^{30}$ found that TLR9 can produce activated receptor (p80) and negative regulator soluble TLR9 (sTLR9) after different hydrolases took effect. sTLR9 can bind the ligands competitively with TLR9, which plays a regulatory role in the initial stage of TLR9 signaling pathway. Lee et $\mathrm{al}^{31}$ reported that the $\mathrm{N}$ terminal TLR9 protolysate produced by hydrolysis of $\mathrm{C}$ terminal activated TLR9 with lysosome and had a negative feedback regulation to TLR9 signaling. Our research confirmed that the levels of TLR9 protein increased in advanced colorectal cancer and the adjacent tissues by Western blot. It is consistent with the results obtained from immunohistochemical detection. In addition, we examined the differential expression of TLR9 relation to the histologic sites and the levels of TLR9-C and TLR9-R proteins raising in advanced colon and rectal cancer tissues, respectively, with TLR9 signal activation. The levels of the downstream molecule NF-kappaB protein increased with upregulation of TLR9-C expression in colon cancer. However, we did not see the levels of NF-kappaB protein increasing in rectum cancer tissues except for upregulation of TLR9-R expression in rectal para-carcinoma tissues. At the same time, it showed that TLR9-C expression was low in rectum cancer tissues. This result suggested that TLR9-R protein may influence NF-kappaB expression through regulating the levels of TLR9-C protein to involve in tumor progression of colorectal cancer. About the studies on the self-regulatory of TLR9 signal, Sinha et $\mathrm{al}^{32}$ have continuously observed that the expression of TLR9 $9^{1-440}$ (the N-terminal segments) had negative feedback to TLR9 signaling and proved the 
protein-protein reaction occurring in the $\mathrm{C}$ terminal of LRR through the crystal structure of TLR9. The researcher thought that this reaction conducted by self-expression of TLR9 $9^{471-1032}$ contributed to the wrong glycosylation and abnormal pathway activation, while disturbing the normal function of TLR9. It conformed to the differential expression of TLR9 signal activation in this study. Of course, it is necessary to further investigate the special functions of TLR9-C and TLR9-R proteins and the roles of downstream factor NFkappaB. Our research preliminary revealed the correlation of the differential expression on TLR9 signal activation in colorectal cancer and the tumor development.

\section{Conclusion}

TLR9 signal activation was involved in the clinical development of colorectal cancer. The differential expression on TLR9 signal activation was associated with histogenesis in colorectal cancer and influenced the levels of downstream molecule NF-kappaB protein, which played an important role in the clinical process of colorectal cancer.

\section{Acknowledgments}

Zhangbin and Zhuangxibing took part in the collection of medical records in this study. Yuansujun and Luoyoujun participated in the experimental process. The authors are grateful for their hard work.

\section{Disclosure}

The authors report no conflicts of interest in this work.

\section{References}

1. Jemal A, Siegel R, Xu J, Ward E, Statistics C. Cancer statistics, 2010. CA Cancer J Clin. 2010;60(5):277-300.

2. Inoue J, Gohda J, Akiyama T, Semba K. NF-kappaB activation in development and progression of cancer. Cancer Sci. 2007;98(3):268-274.

3. Chen K, Huang J, Gong W, Iribarren P, Dunlop NM, Wang JM. Toll-like receptors in inflammation, infection and cancer. Int Immunopharmacol. 2007;7(10):1271-1285.

4. Kolumam GA, Thomas S, Thompson LJ, Sprent J, Murali-Krishna K. Type I interferons act directly on CD8 T cells to allow clonal expansion and memory formation in response to viral infection. $J$ Exp Med. 2005;202(5):637-650.

5. Havenar-Daughton C, Kolumam GA, Murali-Krishna K. Cutting Edge: The direct action of type I IFN on CD4 T cells is critical for sustaining clonal expansion in response to a viral but not a bacterial infection. J Immunol. 2006;176(6):3315-3319.

6. Krieg AM, Yi AK, Matson S, et al. CpG motifs in bacterial DNA trigger direct B-cell activation. Nature. 1995;374(6522):546-549.

7. Chang YJ, Wu MS, Lin JT, Chen CC. Helicobacter pylori-Induced invasion and angiogenesis of gastric cells is mediated by cyclooxygenase-2 induction through TLR2/TLR9 and promoter regulation. J Immunol. 2005;175(12):8242-8252.

8. Droemann D, Albrecht D, Gerdes J, et al. Human lung cancer cells express functionally active Toll-like receptor 9. Respir Res. 2005;6:1.
9. Merrell MA, Ilvesaro JM, Lehtonen N, et al. Toll-like receptor 9 agonists promote cellular invasion by increasing matrix metalloproteinase activity. Mol Cancer Res. 2006;4(7):437-447.

10. Takala H, Kauppila JH, Soini Y, et al. Toll-like receptor 9 is a novel biomarker for esophageal squamous cell dysplasia and squamous cell carcinoma progression. J Innate Immun. 2011;3(6):631-638.

11. Chen R, Alvero AB, Silasi DA, Steffensen KD, Mor G. Cancers take their Toll - the function and regulation of Toll-like receptors in cancer cells. Oncogene. 2008;27(2):225-233.

12. Takeda K, Kaisho T, Akira S. Toll-like receptors. Annu Rev Lmamnol. 2003;21:335-376.

13. Xu L, Wang C, Wen Z, et al. Selective up-regulation of CDK2 is critical for TLR9 signaling stimulated proliferation of human lung cancer cell. Immunol Lett. 2010;127(2):93-99.

14. Ren T, Xu L, Jiao S, et al. TLR9 signaling promotes tumor progression of human lung cancer cell in vivo. Pathol Oncol Res. 2009;15(4): 623-630.

15. Xu L, Wang C, Wen Z, et al. CpG oligodeoxynucleotides enhance the efficacy of adoptive cell transfer using tumor infiltrating lymphocytes by modifying the Th1 polarization and local infiltration of Th17 cells. Clin Dev Immunol. 2010;2010:1-9.

16. Kundu SD, Lee C, Billips BK, et al. The toll-like receptor pathway: a novel mechanism of infection-induced carcinogenesis of prostate epithelial cells. Prostate. 2008;68(2):223-229.

17. Zarember KA, Godowski PJ. Tissue expression of human Toll-like receptors and differential regulation of Toll-like receptor mRNAs in leukocytes in response to microbes, their products, and cytokines. J Immunol. 2002;168(2):554-561.

18. Hemmi H, Takeuchi O, Kawai T, et al. A Toll-like receptor recognizes bacterial DNA. Nature. 2000;408(6813):740-745.

19. González-Reyes S, Marín L, González L, et al. Study of TLR3, TLR4 and TLR9 in breast carcinomas and their association with metastasis. BMC Cancer. 2010;10:665.

20. Tanaka J, Sugimoto K, Shiraki K, et al. Functional cell surface expression of toll-like receptor 9 promotes cell proliferation and survival in human hepatocellular carcinomas. Int J Oncol. 2010;37(4):805-814.

21. Meng Y, Kujas M, Marie Y, et al. Expression of TLR9 within human glioblastoma. J Neurooncol. 2008;88(1):19-25.

22. Väisänen MR, Väisänen T, Jukkola-Vuorinen A, et al. Expression of toll-like receptor- 9 is increased in poorly differentiated prostate tumors. Prostate. 2010;70(8):817-824.

23. Kauppila JH, Takala H, Selander KS, Lehenkari PP, Saarnio J, Karttunen TJ. Increased Toll-like receptor 9 expression indicates adverse prognosis in oesophageal adenocarcinoma. Histopathology. 2011;59(4):643-649.

24. Wang C, Cao S, Yan Y, et al. TLR9 expression in glioma tissues correlated to glioma progression and the prognosis of GBM patients. $B M C$ Cancer. 2010;10:415.

25. Ronkainen H, Hirvikoski P, Kauppila S, et al. Absent Toll-like receptor-9 expression predicts poor prognosis in renal cell carcinoma. J Exp Clin Cancer Res. 2011;30:84.

26. Jukkola-Vuorinen A, Rahko E, Vuopala KS, et al. Toll-like receptor-9 expression is inversely correlated with estrogen receptor status in breast cancer. J Innate Immun. 2009;1(1):59-68.

27. Tuomela J, Sandholm J, Karihtala P, et al. Low TLR9 expression defines an aggressive subtype of triple-negative breast cancer. Breast Cancer Res Treat. 2012;135(2):481-493.

28. Eiró N, González L, González LO, et al. Study of the expression of toll-like receptors in different histological types of colorectal polyps and their relationship with colorectal cancer. J Clin Immunol. 2012; 32(4):848-854.

29. Jin MS, Lee JO. Structures of the toll-like receptor family and its ligand complexes. Immunity. 2008;29(2):182-191.

30. Chockalingam A, Cameron JL, Brooks JC, Leifer CA. Negative regulation of signaling by a soluble form of toll-like receptor 9. Eur J Immunol. 2011;41(8):2176-2184. 
31. Lee S, Kang D, Ra EA, Lee TA, Ploegh HL, Park B. Negative selfregulation of TLR9 signaling by its $\mathrm{N}$-terminal proteolytic cleavage product. J Immunol. 2014;193(7):3726-3735.
32. Sinha SS, Cameron J, Brooks JC, Leifer CA. Complex Negative Regulation of TLR9 by Multiple Proteolytic Cleavage Events. J Immunol. 2016;197(4):1343-1352.

\section{Publish your work in this journal}

OncoTargets and Therapy is an international, peer-reviewed, open access journal focusing on the pathological basis of all cancers, potential targets for therapy and treatment protocols employed to improve the management of cancer patients. The journal also focuses on the impact of management programs and new therapeutic agents and protocols on

\section{Dovepress}

patient perspectives such as quality of life, adherence and satisfaction. The manuscript management system is completely online and includes a very quick and fair peer-review system, which is all easy to use. Visit http://www.dovepress.com/testimonials.php to read real quotes from published authors.

Submit your manuscript here: http://www.dovepress.com/oncotargets-and-therapy-journal 